been in a surgical bed for a prolonged period is a "bed-blocker." On our evidence, most such patients are likely to be appropriately placed.

Preservation and expansion of residential, geriatric, and psychogeriatric facilities are essential if some of the major needs of the aged population are to be met. It would be wrong, however, to expect such an expansion to solve the problem of prolonged surgical bed occupancy by the elderly.

D G SEYMOUR

Cardiff Royal Infirmary,

Newport Road,
Cardiff CF2 1SZ

Ninewells Hospital and Medical School,
Dundee DD1 9SY

R PRINGLE

' Rubin SG, Davies GH. Age Ageing 1975 ;4:142-7.

\section{Comparing images}

SIR,-Change in pathology is accurately reflected by change in radiological images only when the initial and subsequent radiological studies are technically comparable. Every doctor is aware of the pneumonia that can be made to "disappear" by an over-penetrated chest radiograph. It seems less generally appreciated that variation in the setting of window levels and window widths at computed tomography leads to different hard-copy images. It is almost valueless to publish follow-up computed tomograms at different settings from initial studies (Drs A L Harris and I E Smith (14 August, p 475)). I am not questioning the validity of the clinical reports here but simply the validity of the published images.

Gloucestershire Royal Hospital,
Gloucester GL1 3NN

\section{Atropine poisoning in early infancy due to Eumydrin drops}

SIR,-It was with great interest but with growing incomprehension that $I$ read this "Lesson of the Week" (17 July, p 196). Dr P W D Meerstadt describes in detail a number of children severely poisoned by atropine. $\mathrm{He}$ correctly states that physostigmine salicylate is the specific antidote and gives a brief description of its pharmacological properties. (One could, however, question whether it is advisable to administer a dose of $0.5 \mathrm{mg}$ routinely to infants of this age. It would be much more advisable to give a dose per $\mathrm{kg}$ bodyweight-in the case of physostigmine $0.02-0.04 \mathrm{mg} / \mathrm{kg}$, to be repeated as necessary.) We are, however, informed that none of the original patients received this antidote, though no explanation is given for this omission. In an addendum we read that in a further case "physostigmine was of no benefit," but no dose is given.

A little further on Dr Meerstadt suggests that paraldehyde may be preferable to diazepam or phenobarbitone in the control of fits, since the latter "may cause further depression of the central nervous system. ..." Yet on reading the article one notes that one of the patients was indeed treated with diazepam and another with phenobarbitone. Is this no worthy of a comment?

In the treatment of poisoning there are only a few antidotes, and therefore the mainstay of treatment continues to be supportive and symptomatic. The belladonna alkaloids are one of the few substances for which there exists a specific antidote. Since the symptoms in all the patients were serious, and in two cases and 4) no less than life-threatening, then the omission of this specific antidote must be characterised as surprising, to say the least.

It is difficult to know whether this article, as the heading indicates, primarily deals with atropine poisoning per se or whether its main purpose is to condemn the use of atropine for the specific indications mentioned. In either case lack of comment on the treatment of these cases and the superficial discussion of general treatment principles do not make this article a good and distinct "lesson" on atropine poisoning.

Säbylund,

S-692 00 Kumla,
Sweden

${ }_{*}^{*}$ We sent a copy of this letter to Dr Meerstadt, who replies below.-ED, $B M \mathcal{F}$.

SIR,-I reported a series of nine cases of atropine poisoning in early infancy due to atropine methonitrate drops (17 July, p 196) These infants had presented to a children's hospital over a period of 10 years. This was a retrospective study and so I cannot explain why the paediatrician responsible for the care of each infant did not give the specific antidote physostigmine salicylate. In the one case in which physostigmine salicylate was given with no beneficial effect, the dose was $0.25 \mathrm{mg}$ intravenously once only $(0.07 / \mathrm{kg})$. Paraldehyde is preferable to diazepam or phenobarbitone in the management of atropine-induced fits, and in the discussion I have said so.

Finally, the purpose of the article was to report the above cases of atropine poisoning, to condemn the use of atropine methonitrate in the treatment of whooping cough, and to question its value in the management of congenital hypertrophic pyloric stenosis in developed countries. The "lesson" is to avoid the indiscriminate prescription of a dangerous drug which is of questionable value. I had not intended the "lesson" to be an in-depth discussion of the management of atropine poisoning, which is readily available elsewhere.

P W D MEerstadT

Queen Charlotte's Maternity Hospital,

London W6 0XG

\section{Unholy wedlock?}

SIR,-I was interested to read $\mathrm{Dr} J \mathrm{R} \mathrm{D}$ Brown's letter (14 August, p 510) regarding use of hospital beds by general practitioners and would wholeheartedly support his views. Many of us with higher training and qualifications are dubious about the present standards of hospital medicine, especially regarding emergency admissions of our patients. With many of our ablest medical graduates now opting for general practice, standards and enthusiasm are on the increase, as my experiences as a course organiser testify.

Plans to double the number of consultants may only reduce the calibre of people in this grade even further. Perhaps, as Dr Brown says, we should be given six months' trial at running a district general hospital, admitting our own patients and using consultant staff in the correct meaning of the word-to consult for advice when asked. If given the tools, then we will finish the job, and our patients will be very satisfied, as anyone who works in a general practitioner hospital will confirm.

D W WALL

Sutton Coldfield B74 2UE

\section{Ultrasound measurement of the spinal} canal in spinal stenosis

SIR,-I was surprised that your expert writing on spinal stenosis ( 31 July, p 356) stated that "ultrasound is a safe and accurate method of measuring the diameter of the lumbar spinal canal." I was concerned to discover that the reference given to support this statement was a preliminary communication given to the British Orthopaedic Research Society. ${ }^{1}$

The originators of the technique of ultrasound measurement of the spinal canal state that it shows good reproducibility and that this demonstrates the accuracy of the technique. ${ }^{2}$ Other workers have found the technique difficult and not reproducible, ${ }^{3}$ that it does not measure a unique dimension of the spinal canal, ${ }^{4}$ that it is of doubtful value in the individual patient, ${ }^{5}$ and that it does not give sufficient detailed information about the anatomy. ${ }^{6}$ The accuracy of a technique depends, of course, on its freedom from systematic and random errors and a small contribution to error from physical causes. The systematic errors of the technique are unknown and physical contributions to variations have been assessed as greater than the quoted figures for reproducibility. ${ }^{7}$ The experimental design used to establish the figures for reproducibility ${ }^{2}$ has been criticised as it does not allow adequate partition of the variables, the sample size is small, and the statistical calculations do not correspond to those of other authors, ${ }^{7}$ and thus the low value indicating excellent reproducibility cannot be compared with other authors' figures.

It has been suggested that the large random errors should be reduced by averaging, ${ }^{8}$ although Hibbert et $a l^{2}$ did not do this in their study of reproducibility. Because of this effect of averaging it has been suggested that the technique is more suitable for population or epidemiological studies than for diagnosis in the individual patient. ${ }^{.9} \mathrm{I}$ do not see that a technique which is invalid for the individual patient becomes valid when applied to populations.

A serious criticism of the technique is that it is not the anteroposterior diameter but some oblique dimension of the spinal canal that is being measured and that this dimension cannot be defined uniquely, ${ }^{34}$ except perhaps by arbitrarily standardising the method of measurement, especially the angle of inclination of the scanning plane. ${ }^{8}$ There is controversy over the exact origin of the echoes and it is admitted that it is not known what exactly is being measured. ${ }^{2}$ Some workers feel that the shape of the canal is more important than a single measurement, ${ }^{6}$ and the ultrasonic technique gives no information about the shape.

The common sense view that a measurement is necessarily the best estimator of small size or disproportion between a canal and its contents for clinical purposes is not borne out by the experience with pelvimetry. It has been shown that the pelvimetric measurements have no effect on management or outcome of labour ${ }^{10}$ in Caucasian women although the obstetrician who selects patients for pelvimetry on the basis of pelvic examination is predicting successfully which ones will have a difficult labour or need intervention. ${ }^{11}$

I think that before a measurement is accepted as useful in clinical practice it is necessary to know: (a) what exactly is being measured; $(b)$ that the method can be easily applied in practice; (c) that it is valid for individual patients in resolving clinical diagnostic problems when used apart from the clinical information. I do not think that the above points have been established sufficiently well 
for ultrasound measurement of the spinal canal to be accepted into routine clinical practice.

\section{Peter Davies}

\section{Department of Radiology, City Hospital,
Nottingham NG5 1PB}

1 Porter RW, Ottowell D, Wicks M. F Bone foint Surg 1977;59B: $249-50$.

2 Hibbert CS, Delaygue C, McGlen B, Porter RW. Br $\mathcal{F}$ Radiol 1981;54:905-7.

Stockdale MR, Finlay D. Br F Radiol 1980;53:1101-2. Chattman BE. Br $\mathcal{F}$ Radiol $1981 ; 54: 1116$.

Nachemsen A, Asztely M. Br F Radiol 1981;54:11011. Veiga-Pires JA, Beck RD, Kaiser MC. Br $\mathcal{J}$ Radio $1981 ; 54: 269$.

Davies P. Br F Radiol 1982;55:380-1.

- Porter RW. Br $\mathcal{F}$ Radiol $1981 ; 54: 1011$-12.

Brown RF. Madden DA, Ararsese JS, Barnett M, Brown RF :66-74.

" Russell JGB, Richards B. Br f Radiol 1971 ;44:780-4.

\section{Brodrick exhumed again}

SIR,-Professor Bernard Knight writes (7 August, p 393), "Under the present law a doctor need not report any death to the coroner." Does this imply that it is only customary and not mandatory for a hospital doctor to follow the so called " 24 -hour rule" which stipulates: (a) reporting to the coroner deaths of patients which have occurred within 24 hours of admission even when the cause of death is obvious; $(b)$ reporting to the corone falls which occurred within 24 hours prior to death but which obviously did not contribute to the cause of death.

St Luke's Hospital,

Y V PATEL

** We sent this letter to Professor Knight, who replies below.

SIR,-There is at present no legal obligation for a doctor to report a death to the coroner though naturally this is a well established convention to the advantage of the bereaved relatives, the coroner, and the legal machinery generally. The only legal obligation which a registered medical practitioner has, however, is to issue a death certificate if he was the regular medical attendant, though again conventionally this is not done if the doctor either does not know the cause of death or knows or suspects that it was unnatural.

It is the duty of the registrar of births and deaths to scrutinise each certificate sent by doctors and to refer any unacceptable ones to the coroner. The proposed change in the law that I referred to will oblige the doctor to report these conditions directly to the coroner rather than using the registrar as an intermediary screener.

It is certainly not mandatory in the legal sense for a hospital doctor to follow the " 24 hour rule," which is a well accepted but not legally enforceable requirement of many coroners. Some coroners do not in fact insist on this convention.

Though these matters are not covered at present by statute law, it is obviously both advantageous and ethical for the doctor to co-operate with conventional practices to make the disposal of the dead as expeditious as possible, especially for the wellbeing of the relatives.

BERNARD KNIGHT

Institute of Pathology,

Royal Infirmary,
Cardiff CF2 ISZ
Septicaemia due to Yersinia enterocolitica after oral overdoses of iron

SIR,-Dr Kjetil Melby and colleagues (14 August, $p$ 467) comment that there is no evidence that iron compromises phagocytosis This is not actually correct. My colleague $\mathrm{Dr}$ George Drivas of Athens has used our technique of Kupffer-cell study ${ }^{1}$ to show that there is impaired phagocytosis by the Kupffer cells in the iron overload states associated with $\beta$-thalassaemia and homozygous sickle-cell anaemia. ${ }^{2}$ It is likely that excess iron can damage the Kupffer cells by promoting lipid peroxidation.

Southmead Hospital,

E N WARDLE

Bristol

Drivas G, Uldall P, Wardle EN. Br Med $\mathcal{F} 1975$;iii 2 Drivas G. Acta Haematol (in press).

\section{Mastectomy and its consequences}

SIR,-May I, even at this late stage, refer to the reference in the article on the consequences of mastectomy by $\mathrm{Mr} \mathrm{T} \mathrm{M}$ Feeley and others (24 April, $p$ 1246) to administrative shortcomings in the breast prosthesis service. The list of "standard" surgical appliances for which contracts are negotiated by this Department on behalf of hospitals includes 10 different breast prostheses for supply and fitting by the hospital's normal appliance contractor at between $£ 20$ and $£ 40$ (excluding the temporary ones) or for purchase direct in bulk for fitting by the hospital's own qualified staff at two-thirds or less of those prices, depending on quantity bought. So these are not expensive items and a full range to provide adequate patient choice may easily be held. I will gladly give more details to any hospital doctor on request. If an adequate choice is not being provided locally, perhaps the consultant should ask why not.

On Mrs Kenton's point about correct size (5 June, $p$ 1713) surely, as the principal purpose of these prostheses is the very essential one of psychological support, if the patient thinks it is right then it is right.

DHSS,

D STOCKDALE

Blackpool FY2 0UZ

\section{Emporiatrics-travellers' health}

SIR,-In response to the leading article by $\mathrm{Dr}$ M G Schultz (28 August-4 September, p 582) we draw attention to our own emporiatric findings in recent years. Investigations of the original outbreak of legionnaires' disease among package holidaymakers in Benidorm revealed an unexpectedly high rate of illness: $65 \%$ of those in the hotel concerned had been ill, but so had $53 \%$ of similar tourists in other hotels. ${ }^{1}$ Of travellers who contacted us as a result of publicity from this incident $78 \%$ reported illnesses, with respiratory features in $45 \%$, alimentary symptoms in $33 \%$, and other manifestations in $18.5 \% .^{2}$ A later study of 2221 travellers from Glasgow revealed illness in $43 \%$, mainly alimentary, with higher rates in package-deal holidaymakers than in other groups, and more illness in those who had travelled further south, especially to North Africa. ${ }^{3}$ By contrast, illness was reported by only $19 \%$ of visitors to Scotland who returned questionnaires after leaving (unpublished observations). We share the concern of $\mathrm{Dr}$ Schultz, and our investigations continue.

N R GRIST

J H Cossar

Department of Infectious Diseases,

Ruchill Hospital,
Glasgow G20 9NB

D REID

Communicable Diseases (Scotland) Unit, Ruchill Hospital,

1 Reid D, Grist NR, Najera R. Bull WHO 1978;56: Cossar JH, Dewar RD, Fallon RJ, Grist NR, Reid D. 2 Cossar JH, Dewar RD, Fa Practitioner in press).
Reid D, Dewar RD, Cossar JH, Grist NR. F Infect
(965-70.

\section{Where am I?}

SIR,-I read with interest the leading article on transient global amnesia, "Where am I ?" (10 July, p 85), but was surprised that Dr R B Godwin-Austen omitted to mention that clioquinol may cause transient global amnesia. This drug, which has been widely used for the treatment of diarrhoea, may induce amnesia with features indistinguishable from those of classical transient global amnesia. ${ }^{1}$ Unlike the idiopathic variety, clioquinol-induced transient global amnesia lasts longer and in some cases may be accompanied by transient headaches and somnolence. ${ }^{2} 3$ The clinical features are, however, similar enough for this drug to be considered in cases of transient global amnesia. Though clioquinol is the only reported drug to have induced transient global amnesia, it nevertheless suggests an alternative pathogenesis to the usually cited one of mesial temporal ischaemia.

ROBERT TEOH

Johns Hopkins University

School of Medicine,

Baltimore,
Maryland 21205, USA

\section{' Mumenthaler M, Kaeser HE, Meyer A, Hess $T$ I Neurol Neurosurg Psychiatry 1979;42:1084-90. \\ ${ }_{3}^{2}$ Ferrier TM, Eadie MJ. Med f A Aust}

\section{Management of extrapulmonary tuberculosis}

SIR,-I was delighted yet dismayed at the recent article (7 August, p 415) on the management of extrapulmonary tuberculosis; delighted that the authors had highlighted the inadequate regimens of chemotherapy which many of the consultants looking after patients with genitourinary disease were using ; dismayed that some chest physicians are still persisting in suggesting that the chemotherapy of genitourinary tuberculosis should be managed by chest physicians.

Genitourinary tuberculosis is a urological disease. It has its own problems which can be managed only by genitourinary surgeons, and it is mandatory therefore that this manifestation of tuberculosis should be looked after by urologists. To say that because the urologists are using inadequate treatment their cases should be looked after by chest physicians is untenable, as it is the failure of the urologists to be acquainted with the modern regimens of chemotherapy that is at fault not the system.

Urologists should be just as familiar with the regimens of chemotherapy for genitourinary tuberculosis as they are in using the latest 